\title{
Technical note: Effects of attachment of hind teats before cleaning and attachment of front teats on milking characteristics in automatic milking systems
}

\author{
J. Besier, ${ }^{* 1}$ G. Schüpbach-Regula,† O. Wellnitz, ${ }^{*}$ and R. M. Bruckmaier*1 \\ *Veterinary Physiology, and \\ †Veterinary Public Health Institute, Vetsuisse Faculty University of Bern, 3012 Bern, Switzerland
}

\begin{abstract}
Milking characteristics differ between the 4 quarters of a dairy cow udder. In particular, milking time is mostly prolonged in hind quarters compared with front quarters because of the usually higher amount of stored milk. The standard milking routine (STDMR) in both conventional and automatic milking systems (AMS) consists of teat preparation of all 4 quarters, followed by attachment of the 4 teat cups, regardless of the distribution of milk between quarters. In the current study, an alternative teat preparation and milking routine (ALTMR) in AMS was tested, which consisted of cleaning and starting the milking of hind teats before cleaning and attachment of front teats. The hypothesis was based on the fact that hind quarters have usually a longer milking time than front quarters. Starting the milking of hind quarters while the front teats are being cleaned may reduce the difference in the end of milking between front and hind quarters and thus reduce total milking time. Both routines were tested on 5 Swedish dairy farms equipped with AMS in a 4-wk experiment in which treatments were alternated weekly. Total milk yield did not differ between treatments. Machine-on time (MOT) was longer in ALTMR than in STDMR because the difference in milking time between hind and front quarters was less than the time needed to prepare the front teats. However, the longer MOT in ALTMR was compensated by a shorter total preparation time, including the attachment of the first teat cup, as only the hind teats (instead of all 4 teats) were cleaned before milking was started. This resulted in a similar total milking time from start of cleaning of the first quarter until the end of milking of the last quarter in both treatments. Because of the prolonged MOT, average milk flow rate was lower in ALTMR than STDMR. Peak flow rate was higher in ALTMR than
\end{abstract}

Received July 6, 2016.

Accepted December 22, 2016.

${ }^{1}$ Corresponding author: rupert.bruckmaier@vetsuisse.unibe.ch
STDMR, but only in teat cups 1 (first attached, hind quarter) and 3 (third attached, front quarter), whereas main milk flow was higher in ALTMR than STDMR in both front quarters. In conclusion, splitting teat cleaning and the start of milking between hind and front quarters does not prolong total milking time, including teat cleaning. The partially positive effect on peak and main milk flow indicates that the ALTMR is a suitable milking routine in AMS. In herds with a greater difference of milk stored in hind compared with front quarters, a reduced total milking time can be expected for ALTMR.

Key words: automatic milking system, milking routine, teat cleaning, udder preparation

\section{Technical Note}

In both conventional and automatic milking systems (AMS), all 4 teats are usually cleaned and pre-stimulated before teat cup attachment and start of milking. However, milking characteristics differ between the 4 quarters of an individual cow. In particular, milking time is usually longer in hind quarters than in front quarters due to the difference of stored milk $(\sim 43 \%$ in front and $\sim 57 \%$ in rear quarters, respectively; Wellnitz et al., 1999). This difference is only partially compensated by a slightly higher milk flow rate in the hind quarters (Rothenanger et al., 1995; Weiss et al., 2004).

The lag time from start of pre-stimulation until milk ejection depends on the degree of udder filling and is less than 1 min in a full udder but can last up to several minutes if only a small amount of milk is stored in the udder (Bruckmaier and Hilger, 2001). A tactile udder preparation of just $15 \mathrm{~s}$ is sufficient to induce oxytocin release and therefore milk ejection (Kaskous and Bruckmaier, 2011). If the degree of udder filling is low, however, up to 1 min should elapse from the beginning of the tactile stimulation until teat cup attachment to ensure the occurrence of milk ejection immediately when the vacuum is generated at the teat (Kaskous and Bruckmaier, 2011; Vetter et al., 2014). In AMS, 
there is always a short latency period after cleaning and before teat cup attachment due to the necessary change from cleaning device to regular teat cup (Dzidic et al., 2004; Macuhová et al., 2004). Therefore, the cleaning of only 2 teats before attachment might be a suitable combination of tactile stimulation and latency period to ensure milk ejection at the start of milking even at a low degree of udder filling due to short milking intervals (Bruckmaier and Hilger, 2001).

Because of the expected longer milking time in hind than in front quarters (Rothenanger et al., 1995), we investigated the suitability of an alternative attachment strategy (ALTMR), in which the 2 hind teats are cleaned and attached before cleaning and attachment of the front teats. We tested the hypothesis that this modification of the milking routine leads to a reduced total milking time from the start of cleaning of the first teat until teat cup detachment of the last teat in AMS. The reduced total milking time for individual cows may increase the efficiency of the AMS; that is, more cows can be milked during a defined time period.

On each of 5 dairy farms in Sweden equipped with AMS (VMS, DeLaval SA, Tumba, Sweden), we performed a 4-wk experiment. In total, 864 dairy cows (419 Swedish Red, 445 Holstein) were involved in the study. Cows were kept in loose housing and were between 2 and 706 DIM of their first to ninth lactation with a daily milk production of 3 to $52 \mathrm{~kg}$.

Two different teat preparation and attachment routines were tested. The treatments switched every 7 to $8 \mathrm{~d}$ throughout the experimental period; that is, each treatment was used during 2 weekly periods on each farm. The cows had continuous access to the AMS. The standard milking routine (STDMR) comprised teat cleaning and attachment procedures as usually conducted on farms in the field. The cleaning, premilking, and drying phase during the preparation process of the udder was conducted with warm water and air in a separate cleaning cup with the usual settings of the used milking system (Dzidic et al., 2004). The sequence of events is shown in Figure 1. Preparation time (PrepTime) includes the cleaning of the teats and lasts until the first quarter starts milking. Thus, removing the cleaning cup, locating the first teat, and attaching the first teat is included. Therefore, the recorded PrepTime is more than just preparation, and this additional time is similar in both treatments. In STDMR (Figure 1a), the cleaning cup always started with the front teat closest to the robotic arm, which was called the "inner front" teat (IF). This was either the left or the right front teat depending on which side of the cow the robotic arm was installed. Then, the inner hind teat $(\mathrm{IH})$ was cleaned, followed by the outer front teat $(\mathrm{OF})$ and finally the outer hind teat $(\mathrm{OH})$. The attach- ment sequence of milking teat cups was $\mathrm{IH}>\mathrm{OH}>\mathrm{IF}$ $>$ OF. Detachment was individually controlled by the milk flow rate of each quarter. The default threshold level of detachment for each quarter was set at $200 \mathrm{~g} /$ min. In ALTMR (Figure 1b), the hind teats were both cleaned, followed by teat cup attachment and start of milking in these 2 quarters. After that, the front teats were cleaned, teat cups attached, and milking started.

Milking characteristics were recorded by Milk Station Software 16.1Alfa (2007 and 2010), which is available as software for the DeLaval VMS. Recorded and calculated parameters are listed and defined in Table 1. After elimination of milkings with kickoffs (approximately 10\%) and other irregular events, as well as incomplete data sets, 21,788 milking events were used for the statistical data evaluation. Data are presented as arithmetic means and standard errors of the mean (SEM), and SAS software (ed. 9.4; SAS Institute Inc., Cary, NC) was used for statistical analysis. The UNIVARIATE procedure was used for descriptive statistics and to test for normal distribution of the data. Parameters without proof of normal distribution were logarithmized before used in the ANOVA. The MIXED procedure was used to test for significant differences between ALTMR and STDMR. The models analyzed total milk yield (TMY), PrepTime, machine-on time (MOT), and average milk flow (AMF) at the level of the individual milking. For main milk flow (MMF) and peak flow rate (PFR), separate models were run for each quarter. Clustering at the level of the individual cow and farm was accounted for by including farm and cow number as random effects, respectively. Treatment (ALTMR and STDMR) and lactation number (grouped into < third lactation, third and fourth lactations, and $>$ fourth lactation) were analyzed as fixed effects. The interaction between treatment and lactation group was also tested but was not significant for any of the model outcomes. To test for specific effects of expected low udder filling statistical analyses were additionally conducted for subgroups of cows with milking intervals of $>3$ to $<6 \mathrm{~h}$ but a TMY of at least $3 \mathrm{~kg}$.

Results of milking are shown in Table 2. As expected, TMY did not differ between the 2 treatments. Obviously, even the shorter PrepTime in ALTMR provided a sufficient stimulation time on the teats to induce oxytocin release and milk ejection. Furthermore, in the present study, the statistical analysis of milkings with expected low degree of udder filling did not show any difference in milking characteristics between the 2 treatments. This may be due to the additional latency period between cleaning and attachment of the first teat cup (Rasmussen et al., 1992; Kaskous and Bruckmaier, 2011; Vetter et al., 2014). It has been shown before that a teat preparation procedure as short as 15 


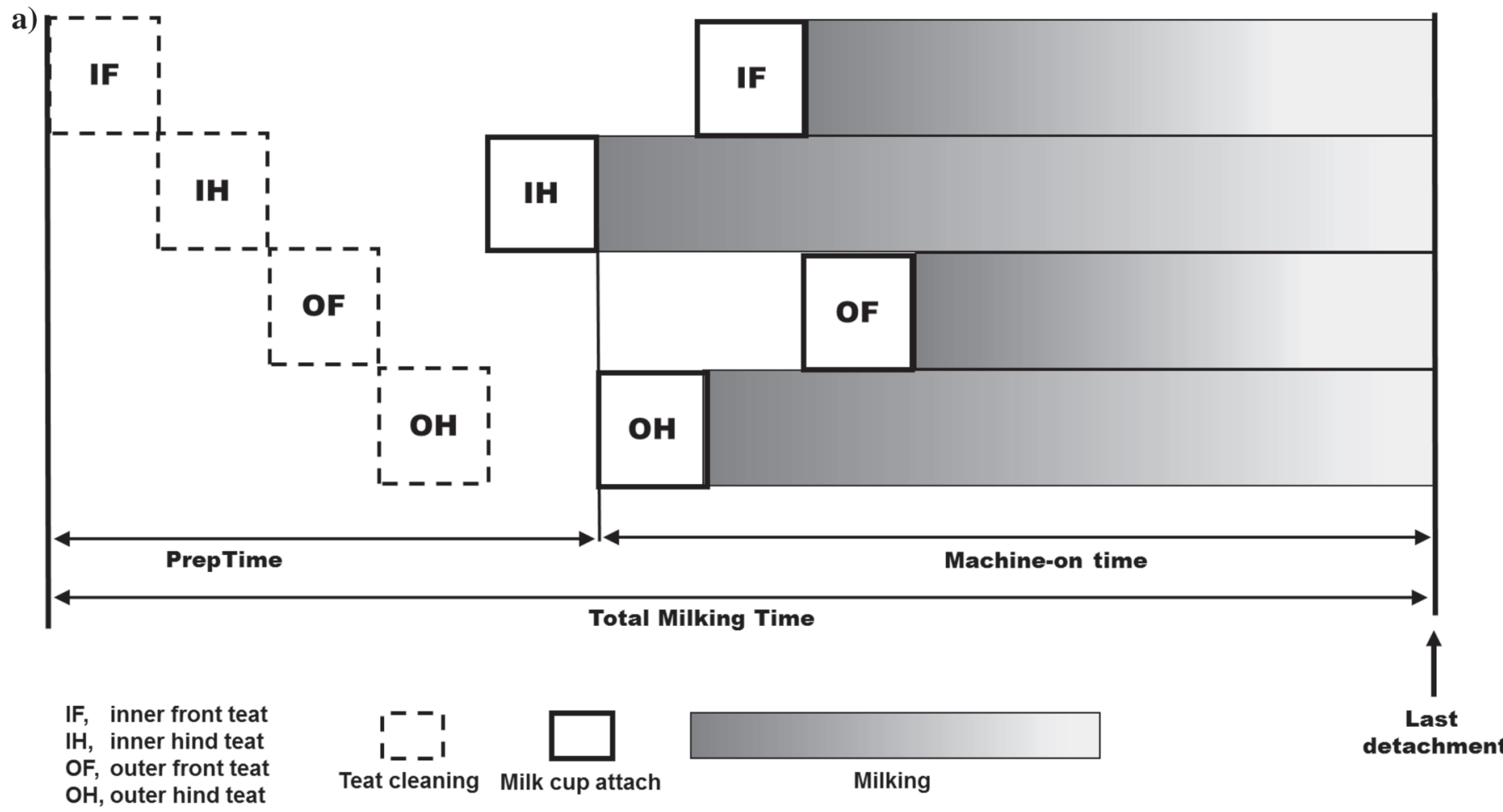

b)

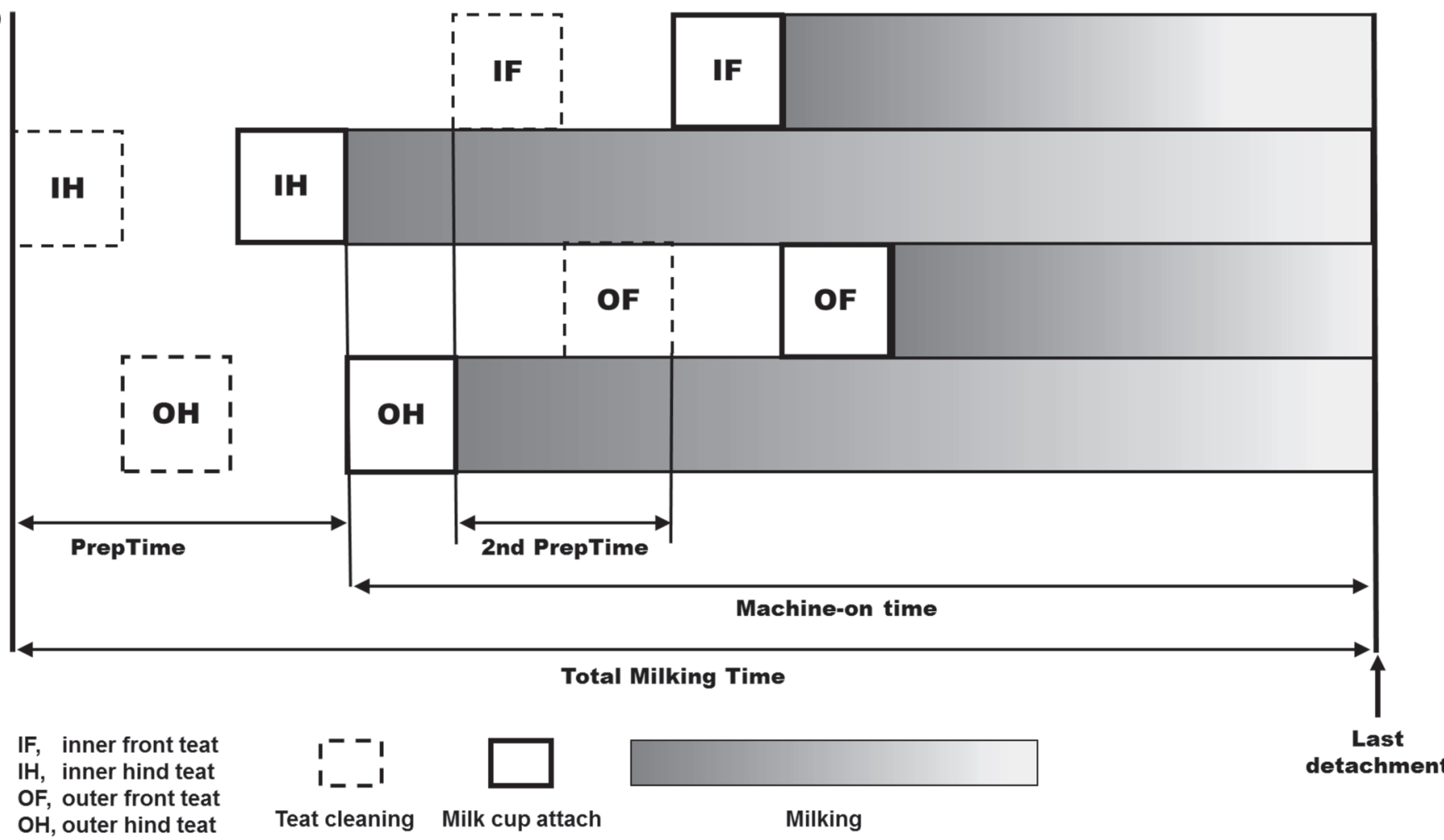

Figure 1. Sequence of teat cleaning and teat cup attachment in the standard milking routine (STDMR; a) and the alternative milking routine (ALTMR; b). Order of cleaning teats in STDMR: inner front teat (IF), inner hind teat (IH), outer front teat (OF), outer hind teat (OH). Order of attachment teat cups in STDMR: IH, OH, IF, OF. Inner or outer teats can be left or right, depending on whether the robotic arm is installed on the left or right side of the cow. Detachment was individually controlled by milk flow rate of each quarter with a default threshold range of detachment when milk flow reached $<200 \mathrm{~g} / \mathrm{min}$. In ALTMR, first IH and OH were cleaned and attached, followed by IF and OF. 
Table 1. Definitions of milking characteristics during the milking in an automatic milking system

\begin{tabular}{|c|c|c|c|}
\hline Milking characteristic & Abbreviation & Unit & Definition \\
\hline Total milk yield & TMY & $\mathrm{kg}$ & Amount of milk obtained during machine-on time (MOT) \\
\hline Preparation time & PrepTime & $\mathrm{s}$ & $\begin{array}{l}\text { Time from the beginning of cleaning until first teat cup is attached; cleaning in } \\
\text { standard procedure: all } 4 \text { teats; first cleaning in alternative procedure: } 2 \text { hind } \\
\text { teats }\end{array}$ \\
\hline Machine-on time & MOT & s & $\begin{array}{l}\text { Time from start of milking of first teat (after teat cup attachment) until last teat } \\
\text { cup detachment }\end{array}$ \\
\hline Total milking time & TMT & $\mathrm{s}$ & PrepTime + MOT \\
\hline $\begin{array}{l}\text { Peak flow rate: } \\
\text { Cup } 1-4\end{array}$ & PFRCup1-4 & $\mathrm{g} / \mathrm{min}$ & Maximum milk flow per quarter in sequence of attachment during any $20 \mathrm{~s}$ \\
\hline
\end{tabular}

$\mathrm{s}$ is sufficient to induce milk ejection, if followed by a latency period up to 1 min (Kaskous and Bruckmaier, 2011). Oxytocin is released from the pituitary in response to teat stimulation and induces milk ejection in all 4 quarters even if only single quarters are stimulated (known as systemic effect, reviewed by Bruckmaier and Blum, 1998). In the present study, the different quarter-individual milk flow traits (PFR and MMF), which were similar or even higher in ALTMR than in STDMR, support the fact that the subsequent cleaning of the 2 hind teats followed by a latency period until teat cup attachment is sufficient to induce milk ejection in all quarters and allows efficient milk removal.

In the ALTMR, 2 teats were cleaned while 2 quarters were already milking. Therefore, MOT was shorter in STDMR than in ALTMR $(P<0.05)$. However, the shorter PrepTime in ALTMR than in STDMR $(P<$ $0.05)$ was expected because only 2 teats were cleaned before attachment. The longer MOT in ALTMR was

Table 2. Milking characteristics in standard (STDMR) and alternative milking routines (ALTMR)

\begin{tabular}{llcc}
\hline Parameter $^{1}$ & Unit & STDMR $( \pm$ SEM $)$ & ALTMR $( \pm$ SEM $)$ \\
\hline TMY & $\mathrm{kg}$ & $13.55 \pm 0.04$ & $13.49 \pm 0.04$ \\
PrepTime & $\mathrm{s}$ & $85.3 \pm 0.3^{\mathrm{a}}$ & $66.1 \pm 0.3^{\mathrm{b}}$ \\
MOT & $\mathrm{s}$ & $382.9 \pm 1.3^{\mathrm{a}}$ & $400.0 \pm 1.3^{\mathrm{b}}$ \\
TMT & $\mathrm{s}$ & $468.2 \pm 1.4$ & $466.1 \pm 1.4$ \\
AMF & $\mathrm{g} / \min$ & $2,261 \pm 7^{\mathrm{a}}$ & $2,138 \pm 6^{\mathrm{b}}$ \\
MMFCup1 & $\mathrm{g} / \mathrm{min}$ & $927 \pm 3$ & $925 \pm 3$ \\
MMFCup2 & $\mathrm{g} / \min$ & $929 \pm 3$ & $931 \pm 3$ \\
MMFCup3 & $\mathrm{g} / \mathrm{min}$ & $858 \pm 3^{\mathrm{a}}$ & $866 \pm 3^{\mathrm{b}}$ \\
MMFCup4 & $\mathrm{g} / \mathrm{min}$ & $848 \pm 3^{\mathrm{a}}$ & $857 \pm 3^{\mathrm{b}}$ \\
PFRCup1 & $\mathrm{g} / \min$ & $1,349 \pm 4^{\mathrm{a}}$ & $1,367 \pm 4^{\mathrm{b}}$ \\
PFRCup2 & $\mathrm{g} / \min$ & $1,369 \pm 4$ & $1,373 \pm 4^{\mathrm{a}}$ \\
PFRCup3 & $\mathrm{g} / \min$ & $1,269 \pm 4^{\mathrm{a}}$ & $1,273 \pm 4^{\mathrm{b}}$ \\
PFRCup4 & $\mathrm{g} / \min$ & $1,255 \pm 5$ & $1,261 \pm 5$
\end{tabular}

\footnotetext{
${ }_{\mathrm{a}, \mathrm{b}}$ Means within a row without different superscripts differ significantly $(P<0.05)$.

${ }^{1} \mathrm{TMY}=$ total milk yield; PrepTime $=$ preparation time; $\mathrm{MOT}=$ machine-on time; TMT $=$ total milking time; $\mathrm{AMF}=$ average milk flow; $\mathrm{PFR}=$ peak flow rate; $\mathrm{MMF}=$ main milk flow; cups $1+2=$ hind teats, cups $3+4=$ front teats.
}

completely compensated by the shorter PrepTime in ALTMR, leading to a similar TMT (PrepTime + MOT) in the 2 treatments. Depending on the distribution of stored milk between front and hind quarters, the MOT can be prolonged, similar, or shorter in ALTMR than in STDMR. In the present study, the time needed to clean the front teats was obviously longer than the difference in milking time between front and hind quarters. In cows with a higher percentage of milk stored in the hind quarters, the ALTMR can reduce MOT. Overall at least, ALTMR does not prolong TMT. If milking of the hind teats lasts much longer than milking of the front teats, which was not the case in the present study, a reduced TMT could be expected. Because AMF was calculated as the ratio of TMY and MOT, AMF was significantly lower in ALTMR than in STDMR. It needs to be mentioned that MOT considers the whole machine-on time from start of milking in the first quarter until the end of milking in the last detached quarter. Therefore, MOT does not represent the duration of attached teat cup on each of the quarters, and an increased effect on each teat through prolonged MOT can be excluded. Peak flow rate was higher in teat cups 1 (hind teat) and 3 (front teat) in ALTMR than in STDMR. Main milk flow was significantly higher in the 2 front quarters in ALTMR than in STDMR.

The overall time that teat cups were attached to each quarter was reduced (data not recorded). Based on the information of individual quarter PFR and MMF, this time was reduced in ALTMR compared with STDMR.

In conclusion, ALTMR leads to a similar total milking time of cows in the AMS and a similar TMY is achieved. Compared with STDMR, the longer MOT was fully compensated by a shorter PrepTime in the ALTMR. A specific time-saving effect of the ALTMR can be expected in less highly bred dairy cows compared with those used in the present study; that is, in animals with a much greater amount of milk stored in the hind quarters than the front quarters. The ALTMR at least 
does not have any disadvantage. This treatment should be tested at a broader level under practical farming conditions and could be generally introduced in robotic milking routines.

\section{ACKNOWLEDGMENTS}

This study was supported by DeLaval International AB, 14721 Tumba, Sweden.

\section{REFERENCES}

Bruckmaier, R. M., and J. W. Blum. 1998. Oxytocin release and milk removal in ruminants. J. Dairy Sci. 81:939-949.

Bruckmaier, R. M., and M. Hilger. 2001. Milk ejection in dairy cows at different degrees of udder filling. J. Dairy Res. 68:369-376.

Dzidic, A., J. Macuhová, and R. M. Bruckmaier. 2004. Effects of cleaning duration and water temperature on oxytocin release and milk removal in an automatic milking system. J. Dairy Sci. 87:41634169.

Kaskous, S., and R. M. Bruckmaier. 2011. Effects of a latency period between pre-stimulation and teat cup attachment and periodic vacuum reduction on milking characteristics and teat condition in dairy cows. J. Dairy Res. 78:97-104.

Macuhová, J., V. Tancin, and R. M. Bruckmaier. 2004. Effects of oxytocin administration on oxytocin release and milk ejection. J. Dairy Sci. 87:1236-1244.

Rasmussen, M. D., E. S. Frimer, D. M. Galton, and L. G. Petersson. 1992. The influence of premilking teat preparation and attachment delay on milk yield and milking performance. J. Dairy Sci. 75:2131-2141.

Rothenanger, E., R. M. Bruckmaier, and J. W. Blum. 1995. Association and dissociation of single quarter and total milk flow in dairy cows: Effects of milking with and without pre-stimulation. Milchwissenschaft 50:63-67.

Vetter, A., H. A. van Dorland, M. Youssef, and R. M. Bruckmaier. 2014. Effects of a latency period between pre-stimulation and teat cup attachment and periodic vacuum reduction on milking characteristics and teat condition in dairy cows. J. Dairy Res. $81: 107-112$

Weiss, D., M. Weinfurtner, and R. M. Bruckmaier. 2004. Teat anatomy and its relationship with quarter and udder milk flow characteristics in dairy cows. J. Dairy Sci. 87:3280-3289.

Wellnitz, O., R. M. Bruckmaier, and J. W. Blum. 1999. Milk ejection and milk removal of single quarters in high-yielding dairy cows. Milchwissenschaft 54:303-306. 